\title{
Smoking cessation clinical practice guideline update and Agency for Healthcare Research and Quality tobacco resources
}

Ernestine W Murray

The Agency for Healthcare Research and Quality (AHRQ), formerly the Agency for Health Care Policy and Research (AHCPR), sponsors and conducts research that provides information on health care outcomes, quality, cost, use, and access. The information helps health care decision makers-patients and clinicians, health system administrators, and policy makers-to make more informed decisions in order to improve the quality of health care services. AHRQ was established specifically to respond to the nation's need for knowledge about the health care system. AHRQ was established in December 1989 to enhance the quality, appropriateness, and effectiveness of health care services, and access to these services, through the establishment of a broad base of scientific research and through the promotion of improvements in clinical practice and in the organisation, financing, and delivery of health care services. ${ }^{1}$

Health plans and system administrators use the findings and tools developed through research sponsored by AHRQ to make choices on how to improve the health care system's ability to provide access and to deliver high quality, high value care. Purchasers use the products of AHRQ sponsored research to obtain high quality health care services. Other potential uses for AHRQ sponsored products include development of performance measures, quality improvement programs, coverage policies, and clinical practice guidelines.

It has been more than two years since the publication of the AHRQ sponsored "Smoking cessation" clinical practice guideline ${ }^{2}$ and the success of that project has exceeded all expectations. Since 1996, additional research has been published on new treatment options for tobacco dependence and addiction. The "Smoking cessation" clinical practice guideline update is a collaborative public health service partnership commissioned by a consortium of federal and private agencies. The consortium includes the AHRQ, Centers for Disease Control and Prevention, National Cancer Institute, National Heart, Lung, and Blood Institute, National Institute for Drug Abuse, Robert Wood Johnson Foundation, and the Center for Tobacco Research and Intervention at the University of Wisconsin, which will analyse important new evidence based data on treatment and intervention strategies.

The reconvened guideline panel, chaired by Michael Fiore, is examining the most recent research in tobacco cessation for the update. The information incorporated in "Smoking cessation, a systems approach", ${ }^{3}$ was taken from the guideline published in April 1996. This document was developed as a guide for health care administrators, insurers, managed care organisations, and purchasers. A fact sheet describing online access for the guideline (AHCPR Publication No 94-0075) and copies of the "Quick Reference's guide for clinicians" and the consumer version of this guideline are available through AHRQ's InstantFAX, a fax-on-demand service that operates 24 hours a day, seven days a week. AHRQ's InstantFAX is accessible to anyone using a facsimile machine equipped with a touchtone telephone handset: dial (+1) 301594 2800, press "1", and then press the facsimile machine's start button for instructions and a list of currently available publications. The guideline products are also available by writing or calling the AHRQ Publication Clearinghouse, PO Box 8547, Silver Spring, MD 20907, USA (weekdays from 9 am to $5 \mathrm{pm}$ eastern standard time), or call (USA only) 1-800-358-9296 (24 hours a day).

The evidence based practice centers (EPCs) were created by AHRQ in 1997 and include 12 centers. The purpose of the EPCs is to collaborate with public and private sector partners to produce evidence reports and technology assessments that include systematic reviews of clinically important topics. The EPCs produce evidence reports that can be used in guideline development by the partner. The evidence report focuses on a few specific clinical questions, goes through peer review, and then is published and widely disseminated.

The National Guideline Clearinghouse (NGC) is a public/private partnership of the AHRQ, the American Medical Association, and the American Association of Health Plans. It is a comprehensive internet based source for clinical practice guidelines that uses all of the features of the world wide web. The NGC has its own live web site and its address is http://www.guideline.gov. The NGC contains structured abstracts of the guideline and other tobacco related guidelines, hot links to full text when possible and ordering information, and syntheses of guidelines on similar topics. It is available free of charge. Thousands of guidelines ultimately will be indexed on the NGC. This will allow rapid access to key recommendations and assessments on hundreds of topics for varied audiences, including: individual physicians and other providers; health care systems and integrated delivery systems; medical speciality and professional email.

emurray@ahrq.gov

E W Murray 
societies; employers and other large purchasers; educational institutions; and state and local governments. The 1996 version of the guideline is available on the NGC and the update will be added once it is completed. For additional information on the NGC, contact Jean Slutsky, project officer, at: jslutsky@ahrq.gov

The US Preventive Services Task Force (USPSTF) is an evidence based independent panel of experts in medicine and prevention, first appointed by the Public Health Service in 1984. In November 1998 the third USPSTF was reconvened by AHRQ. The USPSTF makes recommendations on clinical preventive services which include screening, immunisations, counselling, and chemoprophylaxis; they also produce age specific and risk factor specific recommendation for these services. The "Put prevention into practice" (PPIP) program is the engine that will help translate the evidence that comes out of the USPSTF recommendations into practice for varied audiences, including patients, providers, health plans, purchasers, and policymakers, with the overall aim of improving the quality of preven- tive care. For additional information on the USPSTF, contact David Atkins, project officer, at: datkins@ahrq.gov

AHRQ has funded several grants that have investigated various aspects of smoking and smoking cessation. Research topics have included the medical costs of cigarette smoking, smoking cessation in primary care physician practices, the incidence of relapse among cigarette smokers, and smoking cessation for pregnant adolescents.

To find out more about these and other AHRQ sponsored projects, its research findings, and publications, visit the AHRQ home page at: http://www.ahrq.gov

1 The Omnibus Budge Reconciliation Act of 1989 (Public Law 101-239), Part A, Section 901(b).

2 Fiore MC, Bailey WC, Cohen SJ, et al. Smoking cessation. Clinical Practice Guideline No 18. Rockville, Maryland: US Department of Health and Human Services, Public Health Service, Agency for Health Care Policy and Research, April 1996. (AHCPR Publication No 960692.); < http://www.text.nlm.nih.gov/ftrs/tocview>

3 Fiore, MC, Bailey WC, Cohen SJ, et al. Smoking cessation, a systems approach. Rockville, Maryland: US Department of Health and Human Services, Public Health Service, Agency for Health Care Policy and Research, April 1997. (AHCPR Publication No 97-0698.)

\section{Tobacco Control <http://www.tobaccocontrol.com>}

Visitors to the world wide web can now access Tobacco Control either through the BMJ Publishing Group's home page <http://www.bmj.com $>$ or directly by using its individual URL < http://www.tobaccocontrol.com>. There they will find the following.

- Full text of all issues from Summer 1999 onward (open access to all until February 2000 and thereafter only to subscribers via password)

- Facility to send a rapid response to any article in the journal

- Contents lists of previous issues

- Members of the editorial board

- Subscribers' information

- Instructions for authors

- Details of reprint services.

A hotlink gives access to:

- BMJ Publishing Group home page

- British Medical Association web site

- Online books catalogue

- BMJ Publishing Group books

Suggestions from visitors about features they would like to see are welcomed. They can be sent to the editor at the email address on the inside front cover of this issue, or left via the opening page of the BMJ Publishing Group site or, alternatively, via the journal page, through "About this site". 